\title{
BREAST OMNGER;
}

ROLE OF TAMOXIFEN AS SELECTIVE ESTROGEN RECEPTOR MODULATOR IN PREVENTING BONE LOSS, REDUCING SERUM CHOLESTEROL AND ACTIVITY OF LIVER ENZYMES IN PATIENTS WITH DIFFERENT HORMONAL STATES.

\author{
DR. MUNIZA QAYYUM MALIK, MBBS, M.Phil \\ Department of Pharmacology \\ Fatima Jinnah Medical College and \\ Sir Ganga Ram Hospital, Lahore
}

\author{
DR. SHAHEEN RASHEED, MBBS, MRD \\ Department of Oncology \\ Fatima Jinnah Medical College and \\ Sir Ganga Ram Hospital, Lahore
}

\author{
Dr. Asima Malik, MBBS, M.Phil \\ Department of Biochemistry \\ Fatima Jinnah Medical College and \\ Sir Ganga Ram Hospital, Lahore
}

\author{
Dr. Hurriat Afzal, MBBS, FCPS \\ Department of Surgery \\ Fatima Jinnah Medical College and \\ Sir Ganga Ram Hospital, Lahore
}

\section{DR. RUKHSHAN KHURSHID, Ph.D \\ Department of Biochemistry \\ Fatima Jinnah Medical College and \\ Sir Ganga Ram Hospital, Lahore}

Article Citation:

Malik MQ, Rasheed S, Khurshid R, Malik A, Afzal H. Breast cancer; Role of tamoxifen as selective estrogen receptor modulator in preventing bone loss, reducing serum cholesterol and activity of liver enzymes in patients with different hormonal states. Professional Med J Sep 2009; 16(3): 316-320.

ABSTRACT... Objective: To assess the alterations of serum cholesterol, liver and bone enzyme with breast cancer patient taking tamoxifen with different hormaonal status. Study Design: Experimental study. Period: April to September, 2006 (24 weeks). Setting: The study was carried out on serum samples that were obtained from out department of Oncology, Sir Ganga Ram Hospital of Lahore. Materials and Method: The study included 68 (serum specimen) of breast cancer patients. These patients were different stages of menstruation (postmenarche, perimenopausal and post menopausal). Clinical history and provisional diagnosis were also noted. Results: These patients (68 women) with breast cancer were divided into three major groups; (1) Postmenarche patient, (2) perimenopausal (3) post menopausal status. It is observed that the level of serum cholesterol, ALT and serum alkaline phosphatase in post menarche women were within the normal limits. While women in perimenopausal and post menopausal age groups, had increased level of serum cholesterol $(P<0.01)$ and alkaline phosphatase. Level of ALT however was observed on border line. Conclusions: It is therefore concluded that tamoxifen either prevents or shows no effect on the bone and liver function as well as on cholesterol in postmenarche patients. While in case of perimenopausal and postmenopausal breast cancer patients who received tamoxifen, it may induce increase in cholesterol level and bone resorption, which may be due to decreased level of estrogen. However, further research is needed to reach better conclusions.

Key words: $\quad$ Breast cancer, status of menstruation, biochemical parameters, tamoxifen

\section{INTRODUCTION}

Estrogenic hormones act via the estrogen receptors (ERs), ER-alpha and ER-beta. These receptors are present in more than half of breast tumors, and has been 
the most widely targeted protein in breast cancer therapy ${ }^{1,2}$. Estrogen receptors have been localized to the cell plasma membrane, where signal transduction mediates some estradiol (E2) actions. It is found that the translocation of ERalpha to the membrane in the absence of estrogen is dependent on the serine at position 522 of the ERalpha protein. Mutation of serine 522 to alanine results in a $62 \%$ decrease in membrane localization ${ }^{3,4,5}$. Selective ER modulators (SERMs), tamoxifen and relexofen are reported. Suppression of ER activity by SERMs has proven to be of great benefit in the treatment of breast cancers and also in the prevention of breast cancer in women at high risk for the disease ${ }^{2}$. However, it was found that this minor change of one methylene group of ER transforms a potent estrogenic agonist into an antagonist in vitro ${ }^{5}$.

Tamoxifen, is the first antiestrogen, inhibiting the proliferative effects of estrogen that are mediated through the ER in postmenopausal bone due to its partial estrogen agonist activity. It also helps in prevention of osteoporosis and coronary heart disease however, its long-term use is potentially associated with negative side effects, such as increased risk of thromboembolic disease and endometrial cancer ${ }^{6,7}$. SERM including tamoxifen bind $\mathrm{ER}$, alter receptor conformation, and facilitate binding of coregulatory proteins that activate or repress transcriptional activation of estrogen target genes ${ }^{1}$.

Previous studies have revealed that exogenous estrogen has a beneficial effect on the lipid profile. It is significantly associated with a more favorable lipid profile, including lower total and LDL-cholesterol and triglycerides and higher HDL-cholesterol among controls in post menopausal women. These relations were independent of demographic and metabolic factors and health behaviors. Another study found that the patients who had received six cycles of CMF tomaxifen had shown low $\mathrm{RBC}, \mathrm{WBC}$ and platelet count, elevated levels of SGPT, alkaline phosphatase and lactate dehydrogenase as compared to newly diagnosed breast cancer patients ${ }^{9}$. It is found that the assessment of bone metastases by bone markers of bone formation could be a promising alternative ${ }^{10}$. However some studies found no changes in S-calcium, S-phosphorus or S-alkaline phosphatase ALT, albumin, LDH, calcitonin, or estradiol in patients treated with tamoxifen ${ }^{11,12,13}$.

\section{PURPOSE OF STUDY}

This prospective study was designed to evaluate the effect of adjuvant tamoxifen in estrogen receptor positive breast cancer women (including premenopausal, perimenopausal and post menopausal women) on the level of serum cholesterol, liver/bone enzyme in concomitantly in women with 2nd and 3rd stage breast cancer.

\section{MATERIAL AND METHODS}

Serum samples of 68 consecutive patients of breast cancer, lymph node positive, ER positive stage II \& III being treated at department of Oncology F.J.M.C were taken over a period of 6 months from April to December 2006. The patients were comprised as 12 women with postmenarche (Group A), 23 women with perimenopausal (Group B) and 33 postmenopausal (Group C). All of these patients were given FAC (5Fluoruracil, Doxorubicin and Cyclophosphamite) 6 cycles followed by 20mg Tamoxifen. Level of serum cholesterol, ALT and alkaline phosphatase were estimated by standard kit method ${ }^{14}$.

P-values were calculated by student t-test using SPSS version 11.

\begin{tabular}{|l|l|c|}
\hline Group & Hormonal status & No. \\
\hline A & Post menarche & 12 \\
\hline B & Perimenopausal & 23 \\
\hline C & Postmenopausal & 33 \\
\hline
\end{tabular}


Table. Variations in biochemical parameters in different status of women with breast cancer taking tamoxifen.

\begin{tabular}{|l|l|l|l|l|}
\multicolumn{2}{|c|}{ Values expressed as mean \pm SD } & & \multicolumn{2}{c|}{ No of patients in parenthesis. } \\
\hline Status of women & Age $(\mathrm{yrs})$ & S.chol $(\mathrm{mg} / \mathrm{dl})$ & ALT $(\mathrm{u} / \mathrm{l})$ & AlK. Phos $(\mathrm{KAU})$ \\
\hline Post menarche (12) & $33.14 \pm 4.26$ & $177.1 \pm 57.0$ & $9.17 \pm 5.60$ & $7.49 \pm 2.18$ \\
\hline Perimenopausal (23) & $40.9 \pm 1.56$ & $203.0 \pm 45.53$ & $12.30 \pm 8.16$ & $7.84 \pm 1.88$ \\
\hline Post menopausal (33) & $52.9 \pm 8.54$ & $210.6 \pm 45.77^{*}$ & $12.36 \pm 6.58$ & $8.99 \pm 3.43$ \\
\hline \multicolumn{4}{|c|}{${ }^{*} P=<0.01=$ Significant difference. } \\
\hline
\end{tabular}

\section{RESULTS}

Women with breast cancer were divided into 3 groups i.e. group A comprised post menarche, group B were perimenopausal and group $C$ were post menopausal women. Among these, group A having a mean age of $33.14 \mathrm{yrs}$, group B with mean age 40.9 years and group $C$ with mean age 52.9 years. Level of serum cholesterol, alanine transferase and alkaline phosphatase were estimated in all groups. It is observed that women with post menarche status have low level of serum cholesterol, ALT and alkaline phosphatase as compared to the levels of these parameters with perimenopausal and post menopausal women, however a significant difference $(P<0.01)$ was observed only in the level of serum cholesterol when compared this level with the level of post menopausal women.

\section{DISCUSSION}

Signal transduction pathways of the ER alpha (alpha)and beta (beta)-SERM complexes may help in the new drug discoveries and a menu of preventive medicine in clinical practice ${ }^{8}$.

Present study found a normal level of serum cholesterol, alanine transferase and alkaline phosphatase in patients with postmenarche status when compared these levels with normal subjects (data not shown). Present study in accord with a study found that if tamoxifen was given together with adjuvant chemotherapy in postmenarche patients, no changes in liver enzyme were detected ${ }^{15}$. Some studies reported that adjuvant therapy with selective estrogen receptor modifiers spares bone loss in postmenopausal women but not in postmenarche women $^{16,17}$.
Present study found an increased level of serum cholesterol, alanine transferase and alkaline phosphatase in patients with perimenopausal/post menopausal status when compared these levels with normal subjects (data not shown). However, only cholesterol level was significantly increased in postmenopausal group only. Present study in against with a study found that if tamoxifen was given together with adjuvant chemotherapy in post menopausal patients, a significant change in liver enzyme was detected ${ }^{18}$. Our study is also in contrast to the study who reported that adjuvant therapy with selective estrogen receptor modifiers spares bone loss in postmenopausal women ${ }^{19}$. However study is in accord with a study who reported that tamoxifen using for 5 years may induce a change in the function of liver and bone function ${ }^{20,21}$. The findings of a group of workers showed that bone metabolic markers including alkaline phosphatase would be useful to detect, to monitor, and to predict prognosis of bone metastases. Increased level of alkaline phosphatase was also noted with the passage of level of menstruation. A study, suggest that fibroblast growth factor expressed by a great proportion of malignant breast and it may be one of the factor, involved in the formation of osteosclerotic bone metastases. However a study found that tomaxifen found to maintain bone density ${ }^{22}$.

\section{CONCLUSIONS}

It is therefore concluded that tamoxifen either prevents or shows no effect on the bone and liver function as well as on cholesterol in postmenarche patients. While in case of perimenopausal and postmenopausal breast cancer patients who received tamoxifen, it may induces a change in cholesterol level and bone resorption, which 


\section{may be due to decreased level of estrogen. However, further research is needed to reach a better conclusion. Copyright@ 30 Jun 2009.}

\section{REFERENCES}

1. Osborne CK, Zhao H, Fuqua SA. Selective estrogen receptor modulators: structure, function, and clinical use. J Clin Oncol. 2000 Sep;18(17):3172-86.

2. Katzenellenbogen BS, Frasor J. Therapeutic targeting in the estrogen receptor hormonal pathway. Semin Oncol. 2004 Feb;31(1 Suppl 3):28-38.

3. Jensen EV, Jordan VC. The estrogen receptor: a model for molecular medicine. Clin Cancer Res. 2003 Jun;9(6):1980-9.

4. Goss PE, Qi S, Cheung AM, Hu H, Mendes M, Pritzker $\mathrm{KP}$. The selective estrogen receptor modulator $\mathrm{SCH}$ 57068 prevents bone loss, reduces serum cholesterol and blocks estrogen-induced uterine hypertrophy in ovariectomized rats. J Steroid Biochem Mol Biol. 2004 Sep;92(1-2):79-87.

5. Zhang JX, Labaree DC, Mor G, Hochberg RB. Estrogen to antiestrogen with a single methylene group resulting in an unusual steroidal selective estrogen receptor modulator. J Clin Endocrinol Metab. 2004 Jul;89(7):3527-35

6. Evinger AJ 3rd, Levin ER. Requirements for estrogen receptor alpha membrane localization and function. Steroids. 2005 May-Jun;70(5-7):361-3.

7. MacGregor JI, Jordan VC. Basic guide to the mechanisms of antiestrogen action. Pharmacol Rev. 1998 Jun;50(2):151-96.

8. Jordan VC. The past, present, and future of selective estrogen receptor modulation. Ann N Y Acad Sci. 2001 Dec;949:72-9.

9. Mudali S, Dobs AS, Ding J, Cauley JA, Szklo M, Hill Golden S. Endogenous Post-menopausal Hormones and Serum Lipids: The Atherosclerosis Risk in Communities Study. J Clin Endocrinol Metab. 2004, 960:15-17.

10. Mehreen L, Khanam A. Evaluation of toxicities induced by chemotherapy in breast cancer patients. Biomed Pharmacother. 2005 Oct;59(9):524-7. Epub 2005 Jul 7.

11. Palma MA, Body JJ. Usefulness of bone formation markers in breast cancer. Int J Biol Markers. 2005 JulSep;20(3):146-55.
12. Nielsen HE, Gadeberg CC. Serum calcitonin in patients with osteolytic and osteosclerotic metastases from mammary carcinoma. Acta Radiol Oncol. 1980;19(5):331-3.

13. Zidan J, Keidar Z, Basher W, Israel O. Effects of tamoxifen on bone mineral density and metabolism in postmenopausal women with early-stage breast cancer. Med Oncol. 2004;21(2):117-21.

14. Teitz, N.W. Fundamentals of Chemical Chemistry. 1976. W.B. Saunders Co, Philadelphia p 352 .

15. Kusama M, Kaise H, Nakayama S, Ota D, Misaka T, Aoki $T$. Crossover trial for lipid abnormality in postmenopausal breast cancer patients during selective estrogen receptor modulators (SERMs) administrations. Breast Cancer Res Treat. 2004 Nov;88(1):9-16.

16. Hirvikoski PP, Kumpulainen EJ, Johansson RT. Hepatic toxicity caused by adjuvant CMF/CNF in breast cancer patients and reversal by tamoxifen. Breast Cancer Res Treat. 1997 Jul;44(3):269-74.

17. Coleman RE. Hormone- and chemotherapy-induced bone loss in breast cancer. Oncology (Williston Park). 2004 May;18(5 Suppl 3):16-20.

18. Crivellari D, Bonetti M, Castiglione-Gertsch M, Gelber RD, Rudenstam CM, Thurlimann B, Price KN, Coates AS, Hurny C, Bernhard J, Lindtner J, Collins J, Senn HJ, Cavalli F, Forbes J, Gudgeon A, Simoncini E, CortesFunes H, Veronesi A, Fey M, Goldhirsch A. Burdens and benefits of adjuvant cyclophosphamide, methotrexate, and fluorouracil and tamoxifen for elderly patients with breast cancer: the International Breast Cancer Study Group Trial VII. J Clin Oncol. 2000 Apr;18(7):141222.

19. Takahashi S. [Evaluation of cancer-induced bone diseases by bone metabolic marker] Clin Calcium. 2006 Apr;16(4):49-58.

20. Valta MP, Hentunen $T, Q u Q$, Valve EM, Harjula A, Seppanen JA, Vaananen HK, Harkonen PL. Regulation of osteoblast differentiation: a novel function for fibroblast growth factor 8 Endocrinology. 2006 May;147(5):2171-82.

21. Albukhari AA, Gashlan HM, El-Beshbishy HA, Nagy AA, Abdel-Naim AB. Caffeic acid phenethyl ester protects against tamoxifen-induced hepatotoxicity in rats. Food Chem Toxicol. 2009 Apr 24. [Epub ahead of print]. 
22. Pritchard KI, Paterson AH, Fine S, Paul NA, Zee B, Shepherd LE, Abu-Zahra H, Ragaz J, Knowling M, Levine MN, Verma S, Perrault D, Walde PL, Bramwell VH, Poljicak M, Boyd N, Warr D, Norris BD, Bowman D, Armitage GR, Weizel H, Buckman RA. Randomized trial of cyclophosphamide, methotrexate, and fluorouracil chemotherapy added to tamoxifen as adjuvant therapy in postmenopausal women with node-positive estrogen and/or progesterone receptor-positive breast cancer: a report of the National Cancer Institute of Canada Clinical Trials Group. Breast Cancer Site Group. J Clin Oncol. 1997 Jun;15(6):2302-11.

\section{PREVIOUS RELATED STUDIES}

Mukhtar Ahmad, Muhammad Tahir Majeed, Muhammad Jawaid Sabzwari, Muhammad Riaz, Muhammad Umair.

Breast Cancer; Estimation of total serum sialic acid and its Comparison with ca 15-3 as tumor marker.

Professional Med J Mar 2007; (14)1: 98-103.

M) Mumtaz Begum, Rukhashan Khurshid, Ghazala Ruby, Saleem Akhtar. Breast Cancer; Evaluation of CA 15-3 serum levels.

Professional Med J Sep 2006; 13(3): 338-340.

Khawaja Muhammad Fayyaz, Muhammad Azhar Khan, lqbal Ahmad Khan, Muhammad Shafique. Breast Cancer and Harmones. Professional Med J Jun 1996; (3)2: 103-108.

$\Leftrightarrow \quad$ Khawaja Muhammad Fayyaz, Muhammad Azhar Khan, lqbal Ahmad Khan, Muhammad Shafique. Risk Factors for Breast Cancer. Professional Med J Sep 1997; (4)3: 209-214

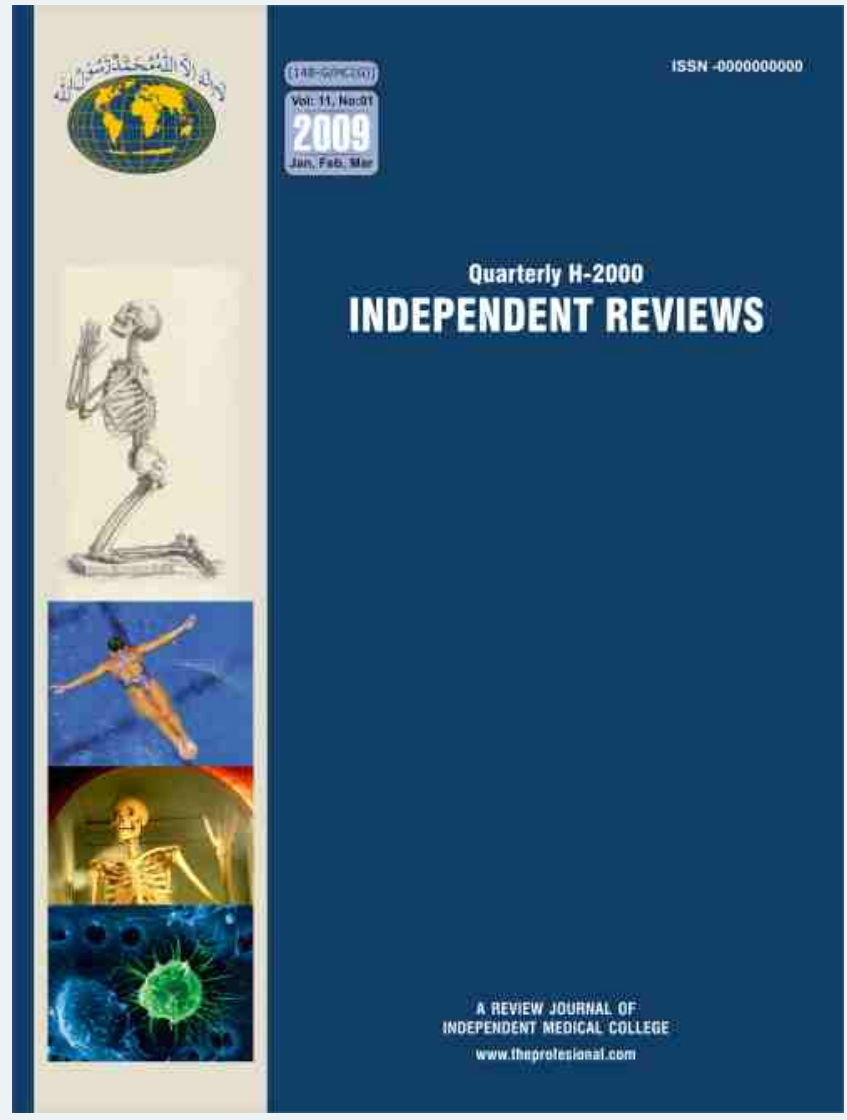

